\title{
A Prospective Study of Three Tests of Glucose Tolerance in Pregnant Women Selected for Potential Diabetes with Reference to the Foetal Outcome
}

\author{
D.R. Hadden, J.M.G. HarLey, T.J. KaJtaR and D.A.D. Montgomery \\ Metabolic Unit, Royal Victoria Hospital and Ante-Natal Diabetes Clinic Royal Maternity Hospital, \\ Belfast, Northern Ireland
}

Received: May 12, 1970, accepted: December 7, 1970

Summary. Results of glucose tolerance tests in a selected group of 1718 patients studied at the thirty-second week of gestation are related, a) mainly to the maternal weight, and b) in part to the maternal age, foetal maturity at delivery and foetal weight at delivery. No clear preference between the three tests emerges, but the $K$ value (glucose disappearance rate after I.V. glucose) appears to be most sensitive to the variables studied. It is not possible to predict the foetal outcome with information obtained from a glucose tolerance test carried out at the thirty-second week of gestation.

Etude prospective de trois tests de tolérance au glucose chez des femmes enceintes choisies à cause d'un diabète potentiel, en relation avec les conséquences pour le foetus

Résumé. Les résultats des tests de tolérance au glucose dans un groupe sélectionné de 1718 patientes étudiées au cours de la trente-deuxième semaine de gestation sont comparés 1. principalement au poids maternel, et 2. en partie à l'âge maternel, à la maturité foetale et au poids foetal lors de la délivrance. Aucune préférence nette n'apparaît entre les trois tests, mais la valeur $K$ (vitesse de disparition du glucose après glucose i.v.) est la plus sensible aux variables étudiées. Il n'est pas possible de prédire les conséquences sur le foetus à partir de l'information obtenue d'un test de tolérance au glucose effectué à la trente-deuxième semaine de gestation.

Prospektive Überprüfung von 3 Glucosetoleranztests bei Schwangeren mit Verdacht auf potentiellen Diabetes in Hin. sicht auf das Schicksal des Foeten

Zusammenfassung. Die Glucosetoleranz-Tests bei einem ausgewählten Kollektiv von 1718 Frauen die in der 32. Schwangerschaftswoche durchgeführt wurden, werden a) vor allem durch das Gewicht der Mutter, b) z.T. aber auch durch ihr Alter, den Reifegrad des Foeten bei der Entbindung und sein Geburtsgewicht beeinflußt. Eindeutige Vorzüge ließen sich für keinen der 3 Tests ermitteln, doch scheint von den untersuchten Variablen der Wert (Glucose-Schwundrate nach i.v. Injektion) am empfindlichsten zu sein. Über das Schicksal des Foeten lassen sich an Hand eines in der 32. Schwangerschaftswoche durchgeführten Glucosetoleranz-Tests keine Voraussagen machen.

Key-words: Glucose tolerance test, oral GTT, cortisone GTT, I. V. GTT, pregnancy, potential diabetes, latent diabetes, gestational diabetes, foetal results, perinatal mortality.
The increased foetal mortality in established maternal diabetes has long been recognized (Harley and Montgomery, 1965). It is less clear, however, whether pregnancy adversely affects the perinatal mortality during the period of a mother's life before she develops clinical diabetes. ${ }^{1}$ Retrospective studies of the foetal outcome during this period, in mothers who subsequentIy developed frank diabetes, have demonstrated a high perinatal mortality rate and an increased incidence of babies of high birth weight (Malins and Fitzgerald, 1965). Prospective studies, however, on the condition of the foetus during this period are still incomplete (Hadden and Harley, 1967). Furthermore, we have little knowledge of the value of tests of carbohydrate

1 The presently accepted classification of the stages in the manifestation of diabetes are:

1. Potential diabetes: Normal oral glucose tolerance but other clinical criteria to suggest a greater risk than normal of developing diabetes.

2. Latent diabetes: Normal oral GTT, but which becomes abnormal temporarily during stress (e.g. pregnancy, or during a cortisone-stressed GTT). This included the group referred to as Gestational Diabetes.

3. Asymptomatic diabetes: Persistent abnormal oral GTT but no symptoms.

4. Clinical diabetes: Abnormal oral GTT with symptoms. tolerance in predicting the outcome of the pregnancy in the individual patient.

During the last six years we have studied 1718 pregnant patients, who fulfilled certain clinical criteria suggestive of potential diabetes, in an attempt to ascertain whether any abnormality of glucose tolerance was of value in predicting the foetal outcome when carried out at the thirty-second week of gestation.

\section{Methods}

The glucose tolerance tests (GTT) and the criteria for interpretation are shown in Table 1. The GTTs were carried out at the antenatal outpatient clinic, by a staff nurse specially trained for this investigation. The mothers attended fasting, in the morning, having been asked to take a normal diet (carbohydrate content $250-300 \mathrm{~g}$ daily) for the previous three days. They sat resting in a group while the tests were carried out. Blood samples were obtained by venepuncture, from an antecubital vein; but an indwelling needle was used for the intravenous test. Blood glucose was measured throughout the study by the Autoanalyser adaptation of the Hoffman technique. 
Blood samples were taken fasting, and at 30,60 , 90 and $120 \mathrm{~min}$ for the oral GTT and cortisone GTT: and fasting and at approximately 10-minute intervals for $60 \mathrm{~min}$ in the intravenous GTT. For the intravenous GTT the absolute rate of glucose disappearance, K, was cent, cortisone 18 per cent and intravenous 17 per cent). Those with abnormal tests varied between 3 and 4 per cent of all patients. They were reviewed at a special antenatal clinical supervised by the authors and were seen at two-weekly intervals and weekly after the

Table 1. Glucose tolerance tests employed during the study

\begin{tabular}{lllll}
\hline Dates & Test & $\begin{array}{l}\text { Glucose } \\
\text { load }\end{array}$ & $\begin{array}{l}\text { Criteria of abnormality } \\
\text { venous blood glucose } \\
\text { and } K \text { value }\end{array}$ & $\begin{array}{l}\text { Number } \\
\text { of tests } \\
\text { performed }\end{array}$ \\
\hline $1963-64$ & Oral GTT & $50 \mathrm{~g}$ & $\begin{array}{l}1 \mathrm{~h}-140 \mathrm{mg} \% \\
2 \mathrm{~h}-110 \mathrm{mg} \%\end{array}$ & 625 \\
$1965-66$ & $\begin{array}{l}\text { Cortisone GTT } \\
\text { (50 mg cortisone acetate }\end{array}$ & $50 \mathrm{~g}$ & $1 \mathrm{~h}-160 \mathrm{mg} \%$ & 545 \\
& $\begin{array}{l}\text { 8 h and 1 h before test) } \\
\text { Intravenous GTT }\end{array}$ & $25 \mathrm{~g}$ & $\begin{array}{l}2 \mathrm{~h}-140 \mathrm{mg} \% \\
K<1.40\end{array}$ & $\begin{array}{r}548 \\
1967-68\end{array}$ \\
\hline
\end{tabular}

estimated from the best fitted slope of the rate of fall of blood glucose from the peak, using the equation $K=\log _{\mathrm{e}} 2 . t / 2$, where $t / 2$ is the time in minutes for the blood glucose to fall to half its previous value (Duncan, 1959). (A perspex calculator was devised for this measurement from the graph on semilogarithmic paper). The criteria for interpretation of the GTT as "normal" or "abnormal" were applied to results of single tests: no estimate of reproducibility was made, as the number of patients was large. The levels of blood glucose were selected for analysis of the oral GTT before the British Diabetic Association suggested levels were available (which suggested a 1 -h figure of $160 \mathrm{mg}$ per cent) (Hadden and Harley 1967). The figure for the abnormal value of $K<1.40$ was obtained from a previous study of glucose tolerance tests in pregnancy at this centre (Billis and Rastogi 1966).

\section{Patients}

All patients who attended the antenatal clinic of the Royal Maternity Hospital, and who were booked for delivery, were screened. (4765 were screened in $1963-64,3080$ in $1965-66$ and 3299 in 1967-68). The screening procedure was carried out by the doctor making the initial clinical examination, and those patients who were not already frankly diabetic and who fulfilled one or more of the criteria shown in Table 2, were selected to have a glucose tolerance test. During each of the three two-year periods the same type of GTT was carried out on all patients - $1963-64$ oral GTT; $1965-66$ cortisone GTT and 1967-68 I.V. GTT). A group of control patients were selected during 1963-64, and during 1965-66 who had none of the maternal selection criteria. Those who were not already frankly diabetic and who fulfilled one or more of the criteria shown in Table 2 were selected for study. The number selected for study varied between 13 and 18 per cent of all patients according to the test used (oral 13 per
Table 2. Patients screening positive to each selection criterion

\begin{tabular}{|c|c|c|c|}
\hline \multicolumn{4}{|c|}{$\begin{array}{c}\text { Maternal selection criteria Test employed } \\
\text { Oral Cortisone Intravenous }\end{array}$} \\
\hline Big baby $(>4.1 \mathrm{~kg})$ & 258 & 194 & 190 \\
\hline Glycosuria & 188 & 67 & 103 \\
\hline Family history of diabetes & 94 & 133 & 150 \\
\hline Obesity ( > $91 \mathrm{~kg})$ & 85 & 21 & 30 \\
\hline Unexplained perinatal & & & \\
\hline death & 37 & 139 & 79 \\
\hline Foetal abnormality & 15 & 69 & 57 \\
\hline Others & 33 & 72 & 84 \\
\hline (Controls) & 50 & 66 & 0 \\
\hline Total patients screened & 4765 & 3080 & 3299 \\
\hline
\end{tabular}

Big baby: Any baby in a previous, or the present, pregnancy which was reliably known to be over $9 \mathrm{lb}(4.1$ $\mathrm{kg}$ ) birth weight.

Glycosuria: Significant glycosuria of at least "one plus" confirmed by routine Clinitest examination on two occasions during the antenatal period.

Family history: A history of frank diabetes in any close relative of the patient or her husband (parent, grandparent, sib, uncle, aunt).

Obesity: Maternal weight of over $200 \mathrm{lbs}(90 \mathrm{~kg})$ at any time during the current pregnancy.

Unexplained perinatal death: A history of intrauterine or neonatal death (up to 7 days), not explicable by known obstetric or other medical hazards.

Foetal abnormality: Patients delivered of a congenitally abnormal foetus in a previous or the current pregnancy.

Others: Patients in whom a GTT was carried out for other criteria, including gross polyhydramnios, and those whose clinical selection was subsequently rejected as not quite fulfilling the necessary criteria.

Controls: Patients selected who were definitely negative to all the screening criteria.

thirty-sixth week. No special alteration to the normal standard of obstetrical care were advised except that patients were not allowed to continue past term and were induced then if labour had not already commenced. (These patients with abnormal tests could be classified as latent, or gestational diabetics if the test was subsequently shown to return to normal post- 
partum; we have avoided using these terms, and although we have used the accepted blood glucose levels of abnormality to analyse the overall foetal results, a major aim of this paper is to assess the effect of the blood glucose during pregnancy as a continuous variable).

\section{Results}

The foetal outcome in the 1718 cases studied has been analysed and forms the basis for this paper. These results have been subjected to computer analysis in an attempt to ascertain whether any of the variables studied could be used to discriminate accurately between the two possible outcomes of pregnancy, i.e., baby alive or baby dead. sions from these figures. There appears to be little difference between the perinatal mortality for normal and abnormal tests in the group dying as the result of fetal abnormalities, although the rate is consistently a little higher in the abnormal group for all three tests. The perinatal mortality rate is consistently higher in the GTT-abnormal group for Rhesus disease and unexplained perinatal mortality in all three tests.

\section{Computer analysis}

This has been carried out only for the cortisone and intravenous glucose tolerance tests. We have posed a number of questions and subjected these to analysis in the hope that we would obtain some definite answers. Table 5 gives the mean, range and variance of the data

Table 3. Foetal results

\begin{tabular}{lllllll}
\hline & \multicolumn{2}{l}{ Oral GTT } & \multicolumn{2}{c}{ Cortisone GTT } & \multicolumn{2}{c}{ I/V GTT } \\
\cline { 2 - 7 } & Normal & Abnormal & Normal & Abnormal & Normal & Abnormal \\
\hline $\begin{array}{l}\text { Deliveries } \\
\begin{array}{l}\text { 28 weeks } \\
\text { Perinatal }\end{array}\end{array}$ & 499 & 129 & 433 & 120 & 457 & 99 \\
$\begin{array}{l}\text { Mortality } \% \\
\text { Hospital }\end{array}$ & 6.2 & 10.8 & 6.0 & $10.8^{*}$ & 7.2 & 8.1 \\
$\begin{array}{l}\text { Perinatal } \\
\text { Mortality }\end{array}$ & & 6.5 & & $5.2^{*}$ & & 4.8 \\
\hline$* \chi^{2}=5.1$ & $p<0.05$ & & & & & \\
\hline
\end{tabular}

Table 4. Causes of perinatal mortality (percent of total babies born in each column)

\begin{tabular}{|c|c|c|c|c|c|c|}
\hline \multirow[b]{2}{*}{$\begin{array}{l}\text { (Total number of } \\
\text { babies born) }\end{array}$} & \multicolumn{2}{|c|}{ Oral G'TT } & \multicolumn{2}{|c|}{ Cortisone GTT } & \multicolumn{2}{|c|}{ I/V GTT } \\
\hline & $\begin{array}{l}\text { Normal } \\
(499)\end{array}$ & $\begin{array}{l}\text { Abnormal } \\
(129)\end{array}$ & $\begin{array}{l}\text { Normal } \\
(433)\end{array}$ & $\begin{array}{l}\text { Abnormal } \\
(120)\end{array}$ & $\begin{array}{l}\text { Normal } \\
(457)\end{array}$ & $\begin{array}{l}\text { Abnormal } \\
(99)\end{array}$ \\
\hline Antepartum haemorrhage & 1.0 & 0 & 0.2 & 0 & 0.2 & 0 \\
\hline Foetal abnormality & 1.8 & 2.3 & 1.8 & 2.5 & 2.6 & 3.0 \\
\hline Rhesus disease & 1.0 & 1.5 & 0.7 & 2.5 & 0.4 & 1.0 \\
\hline Others & 0.6 & 3.1 & 0.2 & 0.8 & 1.7 & 1.0 \\
\hline Unexplained & 1.8 & 3.1 & 3.2 & 4.2 & 1.9 & 4.1 \\
\hline
\end{tabular}

The foetal results are summarized in Table 3 . The perinatal mortalities associated with the oral and cortisone GTTs are very similar, but there is no significant difference between the normal and abnormal tests at the 5 per cent level in either case. The results for the normal and abnormal intravenous tests are of a similar order, and again the difference between them is not significant. The perinatal mortality in the three groups of tests is also compared with the overall hospital perinatal mortality during the same period. Here there is a significant difference between the mortality rate of 10.8 per cent for the abnormal cortisone GTT compared with the overall hospital perinatal mortality rate during the same period but the other differences still do not reach the 5 per cent level of significance.

The causes of perinatal mortality are shown in Table 4 and have been related to the result of the GTT. Since the actual numbers in the different groups are small it is probably unwise to draw any major conclu- which were available for analysis. This has been divided into eight groups, by sex, foetal survival and type of test. Since tests of the normality of distribution were satisfactory, a multiple correlational analysis was utilized. The first question considered was whether any of the blood glucose values obtained were correlated significantly with any of the following variables:

Maternal age.

Maternal weight during first trimester.

Number of previous pregnancies $<28$ weeks.

Number of previous pregnancies $>28$ weeks.

Maturity of foetus at delivery.

Foetal weight at delivery.

The significant correlation coefficients at the 5 per cent level are shown in Table 6: significance is only reached in the larger groups of live births. For the cortisone GTT significant but low-order positive correlations are found with increasing maternal 
Table 5. Mean-values for the different groups, with range and variance

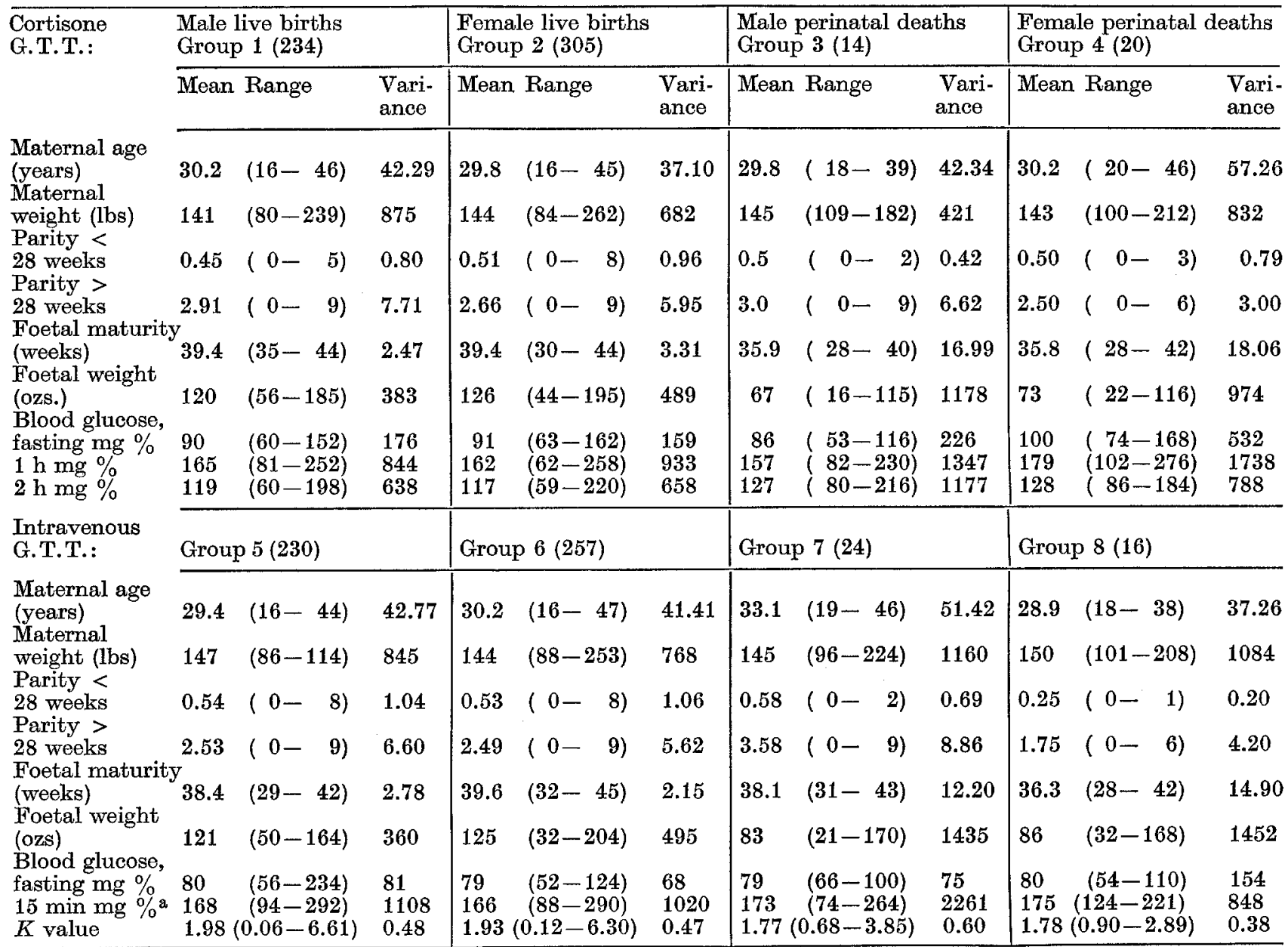

a the 15 min value was taken as that closest in actual time to $15 \mathrm{~min}$ after the I.V. glucose.

Table 6. Computer results: correlation matrix (correlation coefficients, $r$ ) between the blood glucose values and the maternal and foetal criteria

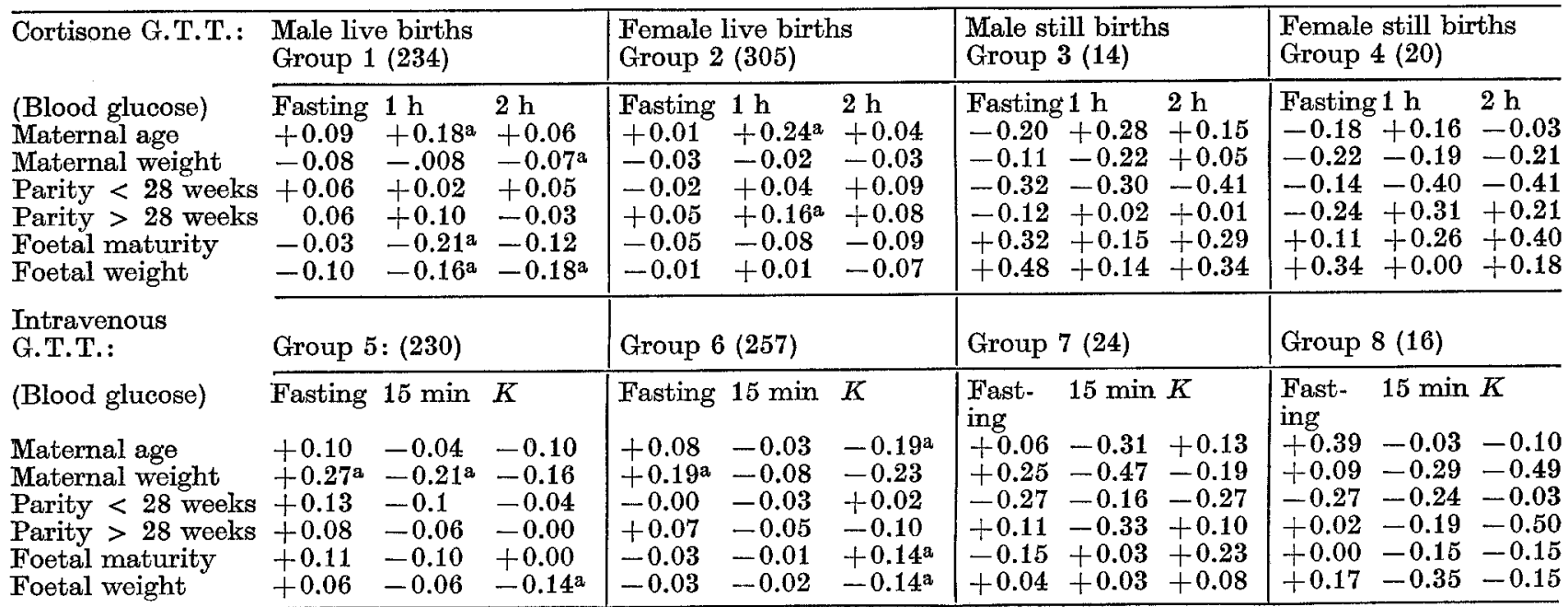


age with the 1-h blood glucose value, whereas a negative correlation is found for male foetal maturity and increasing foetal weight. A similar negative correlation for the foetal weight of male babies is seen with the 2 -h glucose value. An unexpected negative correlation with increasing maternal weight is seen with the $2-\mathrm{h}$ glucose value for male babies.

For the intravenous GTT the maternal age affects the $K$ value negatively for female babies, but the main alteration in this test is found with increasing maternal weight. There is a positive correlation with the fasting blood glucose and a negative correlation with the 15-min level and $K$ value. A negative correlation for the $K$ value is seen with increasing foetal weight, i.e., as the weight of the baby increases the $K$ value falls. The reason for positive correlation of $K$ with the increasing maturity of female babies is uncertain. The $K$ value increases as glucose tolerance improves, so that a positive correlation with the two-hour blood glucose after an oral test would be expected to give a negative correlation with the $K$ value, if the oral and intravenous tests are assessing the same factors.
Maternal age.

Maternal weight during first trimester.

Number of previous pregnancies $<28$ weeks.

Number of previous pregnancies $>28$ weeks.

Maturity of foetus at delivery.

Foetal weight.

The factors found to contribute significantly to the prediction of the three glucose tolerance results (i.e., fasting, one-hour and two-hour values for the cortisone test and the fasting, 15-min and $K$ value for the intravenous test) are shown in Table 7 . The computer analysis was carried out using a multiple linear regression technique for which we assumed that the variables were normally distributed and that there might be a linear relationship between them. The majority of the factors studied adversely affect the GTT results and are underlined, but increasing foetal maturity and weight and increasing maternal weight for the cortisone test, and increasing foetal maturity for the intravenous test in fact improve the GTT values. Maternal weight has the most widespread effect on the intravenous GTT, and maternal age affects both tests to a lesser

Table 7. Computer analysis. Selection factors affecting GTT values for live births (males and females) $(P<0.05)$ (Adverse effects are underlined)

\begin{tabular}{|c|c|c|c|c|c|c|}
\hline \multirow[t]{2}{*}{ GTT } & \multicolumn{2}{|c|}{ Fasting blood glucose } & \multicolumn{2}{|c|}{ 1. $\mathrm{h} / 15 \mathrm{~min}$} & \multicolumn{2}{|c|}{$2 \mathrm{~b} / K$ Value } \\
\hline & Male & Female & Male & Female & Male & Female \\
\hline \multirow[t]{3}{*}{ Cortisone } & & & Maternal & Maternal & \multicolumn{2}{|c|}{ Foetal weight } \\
\hline & . & . & age & age & & . \\
\hline & . & - & $\begin{array}{l}\text { Foetal } \\
\text { maturity }\end{array}$ & . & $\begin{array}{l}\text { Maternal } \\
\text { weight }\end{array}$ & . \\
\hline \multirow[t]{4}{*}{$\begin{array}{l}\text { Intra- } \\
\text { venous }\end{array}$} & $\frac{\text { Maternal }}{\text { weight }}$ & $\begin{array}{l}\text { Maternal } \\
\text { weight }\end{array}$ & $\frac{\text { Maternal }}{\text { weight }}$ & & $\frac{\text { Maternal }}{\text { weight }}$ & $\frac{\text { Maternal }}{\text { weight }}$ \\
\hline & $\cdot$ & . & . & - & - & Maternal age \\
\hline & $\cdot$ & • & - & . & . & Foetal weight \\
\hline & · & . & . & . & - & $\begin{array}{l}\text { Foetal } \\
\text { maturity }\end{array}$ \\
\hline
\end{tabular}

Some of the results in Table 6 are confirmatory, whereas others are mutually conflicting and for these we do not have adequate explanations. An increasing positive correlation for increasing maternal age is understandable, but why this should be significant only with the one-hour value for the cortisone test and not the two-hour level is uncertain. The significant negative correlation for the $K$ value for female babies and the similar trend for the male babies in the intravenous test also confirms these findings. The effect of increasing maternal weight is brought out well by the intravenous test, but this is not supported by the cortisone test where there is a negative correlation with the two-hour value for males. Again the results with increasing foetal weight for the two tests conflict. However, results for foetal maturity in the two tests support each other.

A different technique of analysis is required if the same question is asked in the reverse direction, i.e., "Can the glucose tolerance results be accurately predicted from any of these variables?": degree. Both these factors involve the $K$ value which thus appears to be the most sensitive index when a study of this kind is undertaken.

The third question posed was whether any combination of the seven variables available at the thirtysecond week of gestation will discriminate accurately between the two results of pregnancy, i.e., baby alive or dead:

$\begin{array}{lll} & \text { Cortisone GTT } & \text { I.V.GTT } \\ \text { 1. Blood glucose } & \text { Fasting } & \text { Fasting } \\ \text { 2. Blood glucose } & 1 \mathrm{~h} & 15 \mathrm{~min} \\ \text { 3. Blood glucose } & 2 \mathrm{~h} & K \text { value }\end{array}$

4. Maternal age

5. Maternal weight during first trimester

6. Previous pregnancies $<28$ weeks

7. Previous pregnancies $>28$ weeks

The method adopted was that of discriminant function analysis similar to the multiple linear regression analysis used previously. This gives a predicted 
result of pregnancy for each individual patient. The only significant factor $(P<0.05)$ was the two-hour blood glucose value for the cortisone GTT. This gave a 53 per cent correct prediction of the foetal result but left $\mathbf{4 7}$ per cent of live births misclassified. Although this discriminant function is just significant, the very high misclassification rate renders it of no practical value in predicting the foetal outcome when the test is performed at the thirty-second week of gestation.

\section{Discussion}

A large-scale and prolonged study does not necessarily produce clear-cut results. Although there has been much interest in the outcome of pregnancy in mothers who subsequently become diabetic, and several hypotheses have been advanced to explain the possible interactions of mother, placenta and foetus during this phase of the mother's life, actual prospective data are sparse. O'Sullivan (1970) has produced the only longterm follow-up data (up to 12 years) of mothers who had abnormal oral glucose tolerance in pregnancy, and has confirmed a greater incidence of frank diabetes developing among these mothers than among those whose glucose tolerance had been normal. He has also produced preliminary evidence that foetal wastage in the current pregnancy is greater when an oral GTT is judged abnormal ( 7 viable losses out of $74-9.5$ per cent) than when it is normal (5 viable losses out of 197-2.5 per cent). This significant difference did not appear for a group of 232 random control mothers who had an impaired I.V. GTT result $(K \leqslant 1.34)$ : however there was no worsening of the trend if both an oral and an I.V. test were normal. This data is not dissimilar to the crude foetal results in the present study, although significant differences were not achieved in Belfast for any type of GTT. Nevertheless it does not at present seem likely that attempts at more sophisticated analysis of various techniques of glucose tolerance in pregnancy will necessarily improve this discrimination.

The present study has shown the futility of attempting to predict the foetal result from knowledge of an isolated glucose tolerance test at the thirty-second week of pregnancy. The question of whether further repetition of the same test, or of additional types of GTT, would alter this conclusion remains open. Kahn et al. (1969) have investigated this problem in the offspring of two diabetic parents: although it is a simple statistical fact that the more often any test is repeated the greater is the chance that certain predetermined criteria will be exceeded, we feel that the large number of individual patients involved in the present series should produce acceptable data at least of a trend, and this does not appear. O'Sullivan, Gellis and Tenny (1966) in a similar large-scale study in Boston found that maternal age was the only factor of significance to blood sugar levels after a glucose load when other factors, such as length of gestation, parity and maternal weight were held constant. They suggested that both maternal obesity and the birth of a large baby might be of special importance to the future development of diabetes in the mother. No knowledge yet exists as to the possible effect of these variables on the ultimate development of diabetes in the child.

The correlation matrices for the cortisone and intravenous tests are chiefly interseting for the sustained low order of correlations achieved, even with the relatively large groups studied. Although some of these reach a 5 per cent level of significance, there is no outstanding trend: in particular no significant relations at all are found among the foetal losses, although the groups here are small.

Drury and Timoney (1970) in a large study of the same clinical problem in another Irish city have preferred the oral glucose tolerance test, and used rather different selection criteria, with particular emphasis on maternal glycosuria; they have analysed the outcome of pregnancy in those who had an abnormal test during pregnancy followed by a normal test post-partum: when all foetal deaths are included the perinatal loss was 9 per cent which is similar to that in the present study. Whether treatment of these patients with abnormal glucose tolerance tests in pregnancy will reduce the perinatal death rate is currently under evaluation in Aberdeen (Sutherland et al. 1969): we feel that as the glucose tolerance test is such a poor indicator of foetal results that analysis of a trial where the inclusion of a mother is based purely on the glucose tolerance test may not reveal the whole picture.

Although there is now general agreement on the terminology of the various possible stages in the natural history of diabetes, our clinical selection criteria differ somewhat from those used by others: in particular we have taken $9 \mathrm{lb}(4.1 \mathrm{~kg})$ rather than $10 \mathrm{lb}(4.5 \mathrm{~kg})$ as the index of a big baby. These criteria have given a population sample of 13 to 18 per cent of all mothers attending the antenatal clinic: we have no knowledge of how many of these selected mothers in fact carry a diabetic genetic factor, but we do have evidence that mothers who do not fall into the selected group are very much less likely to have an abnormal GTT (Hadden and Harley, 1967). It is probable that the sample selected is adequate to allow assessment of the influence of glucose tolerance in pregnancy on the foetal outcome, and of the individual significance of the selection criteria.

Hoet (1969) has suggested on the basis of experimental measurements intrapartum that glucose-insulin homeostasis in the normal foeto-placental unit depends entirely on the flexible and rapidly changing glucoseinsulin equilibrium in the mother. Whether this homeostasis has any direct bearing on foetal growth, or foetal survival has not yet been entirely confirmed. The retrospective studies of both foetal weight and foetal survival in mothers ultimately presenting at a diabetic clinic (Malins and Fitzgerald, 1965) do not throw light on whether these factors are directly related to mater- 
nal blood glucose, or indirectly determined through a genetic mechanism (Farquhar, 1965). Several authors, however, have demonstrated a relationship between maternal hyperglycaemia and hyperplasia of the foetal islets (Pedersen, 1967), and Naeye (1965) showed a positive correlation between this islet hyperplasia and the percentage of foetal overweight. O'Sullivan et al. (1966) have shown that treatment with insulin and diet of 307 mothers with an abnormal $(100 \mathrm{~g})$ oral glucose tolerance test at any time in pregnancy significantly lowered the blood glucose in the post-absorptive state, and this was associated with a reduction in the number of $9 \mathrm{lb}$. babies born from 13.1 per cent to 4.3 per cent of the selected groups: however, there was no reduction in foetal mortality. Further analysis of the importance of the various selection criteria used in the present study, and of the effect of foetal weight on survival is in progress (Hadden et al., 1970). It is to be hoped that these mothers will be re-investigated at some future date, when the actual incidence of frank diabetes in both mother and offspring can be determined.

Acknowledgements: We are grateful to the consulting staff of the Royal Maternity Hospital for permission to investigate patients under their care and to Professor $\mathbf{J}$. M.H. Pinkerton for his interest and support for this study. Mr. D.W. Neill, M. Sc., M.C. Path., F.R.I.C., Clinical Biochemist and his staff provided the biochemical data. Dr. J.D. Merrett, Lecturer in Medical Statistics, Queen's University of Belfast, has advised and assisted with the statistical and computer aspects of this study. Sister M.E. Good and staff nurses J. Fannin, J. Pinkerton, M. Nutt of the Royal Maternity Hospital, and numerous other colleagues have been involved with this study over the years and we are most grateful to them for their assistance.

\section{References}

Billis, A., Rastogi, G.K.: Studies in methods of investigating carbohydrate and metabolism in pregnancy. Diabetologia $2,169-177$ (1966).

Duncan, L.J.P.: The intravenous glucose tolerance test. Quart. J. exp. Physiol. (London) 41, 85-96 (1956).

Drury, M.I., Timoney, F.J.: Latent diabetes in pregnancy. J. Obstet. Gynaec. Brit. Cwlth. 77, 24-28 (1970).

Farquhar, J.W.: The influence of maternal diabetes on fetus and child. Recent Advances in Paediatrics $3 \mathrm{rd}$ ed., ed. Gairdner, D., p. 121. London: Churchill 1965.
Hadden, D.R., Harley, J.M.G.: Potential diabetes and the fetus. J. Obstet. Gynaec. Brit. Cwlth. 74, 669-674 (1967).

- Kajtar, T.J., Harley, J.M.G., Montgomery, D.A.D.: Glucose tolerance, potential diabetes and the fetus - a computer-assisted prospective study of the relations between 3 tests of glucose tolerance, maternal criteria of potential diabetes and the fetal result. Excerpta Medica Internat. Congr. Series No. 209, p. 31 (1970).

Harley, J.M.G., Montgomery, D.A.D.: Management of pregnancy complicated by diabetes. Brit. med.J. 1965 I, 14-17. (1965).

Hoet, J.J.: Normal and abnormal fetal weight gain. Fetal autonomy (Ciba Foundation Symposium), ed. G.E.W. Wolstenholme and Maeve O'Connor, p. 186. London: Churchill 1969.

Hoffiman, W.S.: Rapid photoelectric method for determination of glucose in blood and urine. J. biol. Chem. 120, 51-55 (1937).

Kahn, C.B., Soeldner, J.S., Gleason, R.E., Rojas, L., Camarini-Davalos, R.A., Marble, A.: Clinical and chemical diabetes in offspring of diabetic couples. New Engl. J. Med. 281, 343-347 (1969).

Malins, J.M., Fitzgerald, M. G.: Childbearing prior to recognition of diabetes. Recollected birth weights and stillbirth rate in babies born to parents who developed diabetes. Diabetes 14, 175-178. (1965).

Naeye, R.L.: Infants of diabetic mothers; a quantitative, morphologic study. Pediatrics 35, 980-988 (1965).

O'Sullivan, J. B.: Gestational diabetes and its significance. In "Early Diabetes" ed. R.A. Camarini-Davalos and H.S. Cole, Advances in Metabolic Disorders, Suppl. I, p. 339-344. New York: Academic Press, 1970.

- Gellis, S.S., Tenney, B.O.: Gestational blood glucose levels in normal and potentially diabetic women related to the birth weight of their infants. Diabetes 15, 466470 (1966).

- - Dandrow, R.V., Tenney, B.O: The potential diabetic and her treatment in pregnancy. Obstet. and Gynec. 27, 683-689 (1966).

Pedersen, J.: The pregnant diabetic and her newborn, p. 71. Copenhagen: Munksgaard (1967).

Sutherland, H.W., Bewsher, P.D., Cormack, J.D., Stowers, J.M. : Evaluation of the use of chlorpropamide in chemical diabetes diagnosed during pregnancy. Presented to the European Assn. for the Study of Diabetes, Montpellier (1969).

D. Hadden

Metabolic Unit

Royal Victoria Hospital

Grosvenor Road

Belfast, BT $126 \mathrm{BA}$

Northern Ireland 